\title{
Resilience of Past Landscapes: Resilience Theory, Society, and the Longue Durée
}

\author{
Charles L. Redman and Ann P. Kinzig
}

\begin{abstract}
Resilience theory is an expanding body of ideas that attempts to provide explanations for the source and role of change in adaptive systems, particularly the kinds of change that are transforming. Scholars from various disciplines have contributed to the current state of this formulation. This article proposes that resilience theory would benefit from an increasing collaboration with archaeologists, who would provide a long-term perspective on adaptive cycles. Although archaeologists and anthropologists have written provocatively about studying the resilience of past and present societies, such an approach has not become common in these disciplines. We suggest, however, that a resilience framework offers a potential mechanism for reinvigorating the conceptual base of archaeological and anthropological disciplines. To make this case, we (1) highlight three features of resilience theory, including cross-scale interactions, information flow, and phases of the adaptive cycle; (2) examine the extent to which purely natural or social science analyses would give complementary or contradictory conclusions; and (3) discuss the implications of using a long-term integrative perspective for understanding linked social and ecological systems.
\end{abstract}

\section{INTRODUCTION}

Resilience theory seeks to understand the source and role of change, particularly the kinds of change that are transforming, in adaptive systems (Holling et al. 2002:5, Levin 1999). It is a theory of dynamic cycles that are linked across spatial and temporal scales. At the core of resilience theory is the adaptive cycle, which is represented by a "figure eight" as shown in Fig. 1 (Holling 2001:394-395). Individual adaptive cycles are nested in a hierarchy across time and space (see Fig. 2). These nested hierarchies may have a stabilizing effect due to the fact that they provide the memory of the past and of the distant to allow recovery after change occurs. They may also have a destabilizing effect when dynamics across scales become "overconnected" or "brittle," allowing smallscale transformations to "revolt" and explode into larger-scale crises. Taken together this theoretical framework is called "panarchy" (Gunderson and Holling 2002).

Four key features of ecosystems provide the underlying assumptions of resilience theory (Holling and Gunderson 2002:25-27). First, change is neither continuous and gradual nor consistently chaotic. Rather, it is episodic, with periods of slow accumulation of "natural capital" punctuated by sudden releases and reorganizations of those legacies. This episodic behavior is caused by interactions between fast and slow variables. Second, spatial and temporal attributes are neither uniform nor scale-invariant; rather, patterns and processes are patchy and discontinuous at all scales. Therefore, scaling up from small to large cannot be a process of simple aggregation. Third, ecosystems do not have a single equilibrium with homeostatic controls to remain near it; instead, multiple equilibria commonly define functionally different states. Destabilizing forces are important in maintaining diversity, flexibility, and opportunity, whereas stabilizing forces are important in maintaining productivity, fixed capital, and social memory. Fourth, and finally, policies and management that apply fixed rules for achieving constant yields, independent of scale and changing context, lead to systems that increasingly lose resilience, i.e., to systems that suddenly break down in the face of disturbances that previously could be absorbed. Because ecosystems are moving targets, management has to be flexible and work at scales that are compatible with the scales of critical ecosystem and social functions. These critical scales may themselves change over time. The key to enhancing system resilience is for individuals, their institutions, and society at large to develop ways to learn from past experiences, and to accept that some uncertainties must inevitably be faced. 
Fig. 1. A stylized representation of the four ecosystem functions ( $\mathrm{r}, \mathrm{K}, \Omega$, and $\alpha$ ) organized into an adaptive cycle, adapted from Holling and Gunderson (2002) and reprinted with permission of Island Press, copyright 2002.

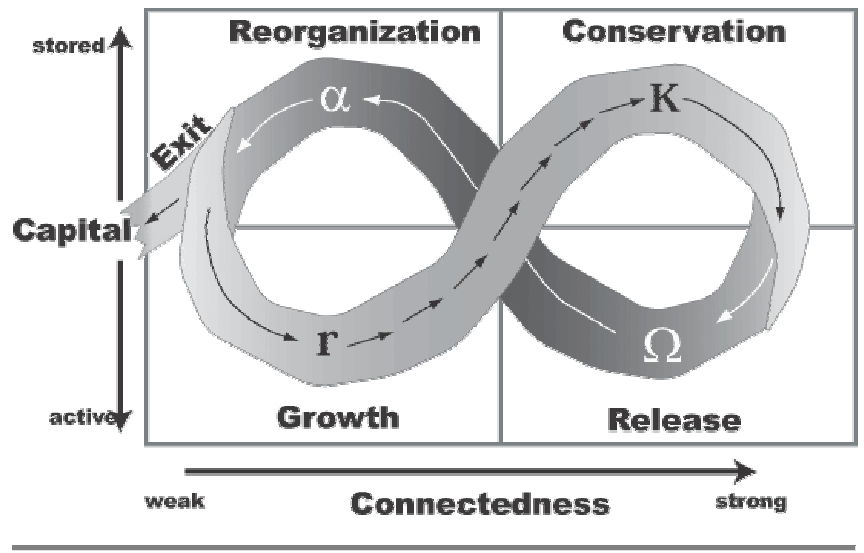

In more traditional views, ecosystem succession is seen as being controlled by three functions. The first is release, represented by the $\Omega$ phase in Fig. 1, in which the tightly bound accumulation of biomass becomes increasingly fragile until it is suddenly released by external agents. Exploitation, the second function, is represented by the $\mathrm{r}$ phase in Fig. 1; this phase emphasizes the rapid colonization of recently disturbed areas. The third function is conservation, represented by the $\mathrm{K}$ phase in Fig. 1, which emphasizes the slow accumulation and storage of energy and material (Holling and Gunderson 2002:3335). Resilience theorists add a key fourth function: reorganization or the $\alpha$ phase, in which resources are reorganized into a new system to take advantage of opportunities. The innovation here is that this "new" system may resemble its predecessor or have fundamentally new functional characteristics, i.e., be in the same or a new "basin of attraction" in a system that has multiple stable states. These four phases have been organized into an "adaptive cycle" metaphor that makes it possible to analyze specific ecosystem trajectories against this theory.

Resilience theory has added two additional features to our understanding of system dynamics in general and of succession in particular. The first is that change is ultimately inevitable and repeated, although repeated cycles may not follow the same pathway or result in analogous systems. The triggering event of release can occur as the result of an internal change in the system, and the $\mathrm{K}$ phase is no longer viewed as a stable phase interrupted only by external perturbations. The second feature, as previously mentioned, is that these adaptive cycles appear to occur across scales, although not continuously. Instead, it is assumed that there are only a handful of spatiotemporal scales, ranging from small-and-fast to large-and-slow, that exhibit strong signatures in the system, and it is the interactions among adaptive cycles at these different characteristic scales that determine resilience dynamics.

As shown in Fig. 2, small-and-fast adaptive cycles may go through frequent periods of creative destruction; in many cases, the "memory" imposed by the large-and-slow adaptive cycles would mean that the small-and-fast levels would re-enter the same or similar adaptive cycles, as illustrated by the "remember" arrow. For example, families may disintegrate due to divorce, but reconstituted families follow the designs deemed "acceptable" by cultural or religious institutions, including most prominently parent-child nuclear families. In some cases, however, tight connections among small-and-fast cycles, or between small-and-fast and intermediate cycles, might mean that creative destruction at the smallest levels would precipitate concurrent destruction and potential flips into fundamentally new adaptive cycles at larger levels, as represented by the "revolt" arrow. This might occur, for instance, if enough families adopted fundamentally new household arrangements to force changes in higher levels of society.

We believe that this theoretical framework could benefit from collaboration with archaeologists, who use information from time scales that are accessible to few other scientists and who link patterns of human response and behavior over broader levels of social organization, e.g., household to civilization, than most other social scientists. These strengths within the field of archaeology can cast new light on linked dynamics across space and time, revealing nuances, contradictions, or knowledge inaccessible over shorter time scales or narrower organizational scales.

In the following section, we elaborate on the key potential contributions that archaeologists and the field of resilience theory can make to each other. We (1) highlight three features of resilience theory, including cross-scale interactions, information flow in the panarchy, and phases of the adaptive cycle; (2) examine the extent to which purely natural or social science analyses would give complementary or contradictory conclusions; and (3) discuss the implications of using a long-term, integrative perspective for understanding linked social and 
ecological systems. In the final section, we offer a brief recap of the ways in which a "deep time" perspective could enhance resilience theory and offer some suggestions for future research.

Fig. 2. "Remember" and "revolt" cycles across levels of the panarchy. Resilience theory emphasizes a synchronic interpretation of interactions in which small-and-fast, intermediate, and large-and-slow cycles are simultaneously operating. "Revolt" dynamics occur from small to large scales, whereas "remember" dynamics occur from large to small. Many small-and-fast adaptive cycles, e.g., households, would be encompassed by a single or a few large-and-slow adaptive cycles, e.g., states, cultures. An alternative use of the model is to view these cycles diachronically, and assume that diachronic movements between scales mimic the ebb and flow of the scope of control of centers of power in society. This figure is reprinted with permission of Island Press, copyright 2002.

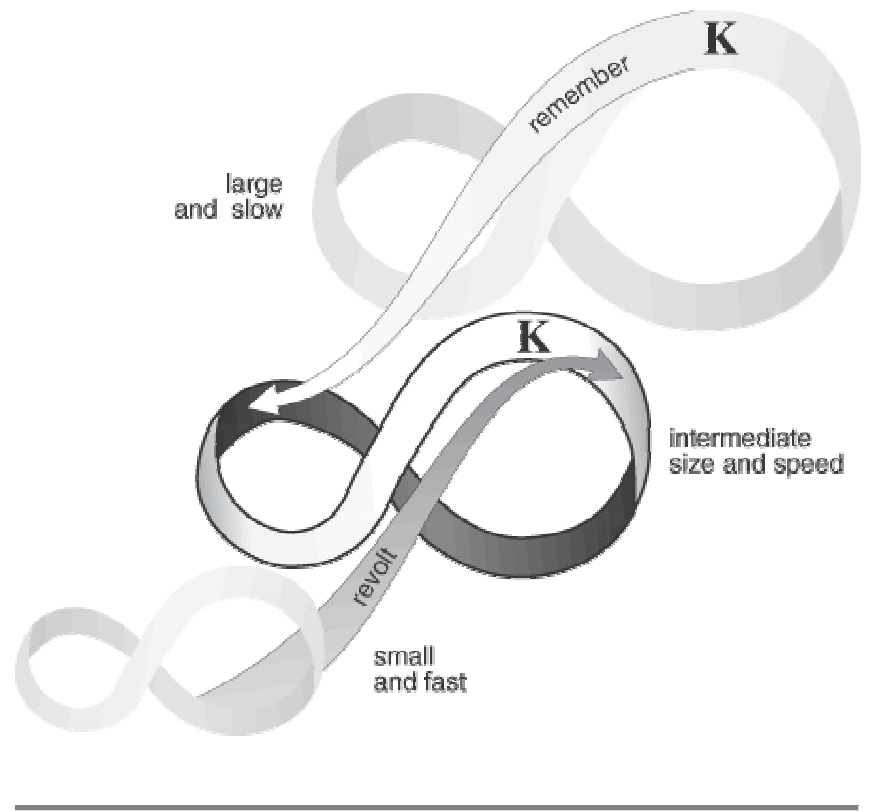

\section{POTENTIAL CONTRIBUTIONS OF COLLABORATION}

\section{Overview}

Conceptualizations of adaptive cycles and panarchy have arisen independently in ecology, archaeology, and economics, among other fields (e.g., Adams 1978, Schumpeter 1987, Tainter 1988, Redman 1999, Holling 2001). We concentrate here on the conceptualization forwarded by Holling in the field of ecology, not because it is necessarily superior to the other conceptualizations, but because it is being widely adopted and is serving as the basis for some compelling international collaborations devoted to enhancing resilience and regional sustainability, largely through the auspices of the Resilience Alliance (see http://www.resalliance.org). From the outset, the proponents of the Hollingesque perspective have recognized the importance of supplementing their ecological perspective with those of various social scientists, and they have expanded and refined their conceptualization with the collaboration of mathematicians, economists, and political scientists, among others (Holling 1973, Gunderson et al. 1995, Holling 2001, Gunderson and Holling 2002). Participating economists have usefully incorporated notions of markets, pricing, and future discounting into refinements. Other social scientists have begun to incorporate notions of constraints and opportunities provided through the development of social and political institutions (e.g., Ostrom 1999a, Westley 1995) and effects of social learning and traditional knowledge on resource management (e.g., Berkes and Folke 1998, 2002). Further issues have been identified but have only begun to be addressed, including the organization of channels of communication, the adoption or rejection of technologies, and the intersection of fast and slow cycling over long time periods.

In the spring of 2002, the authors gathered together archaeologists with research interests in the American Southwest, the Mayan forest, Southern Europe, and the Near East to explore to what extent the data expertise of archaeologists representing both prehistory and history could contribute to the further refinement of resilience theory, and how resilience theory could simultaneously enhance the archaeological understanding of the distant past. The archaeological perspective encapsulates long-term records of countless human societies at various spatial and organization scales in different biogeographic regions of the world. Five key areas of contribution were identified.

First, scholars of contemporary situations usually have to content themselves with investigating an adaptive cycle that is truncated, i.e., that has not yet completed a full cycle, whereas archaeological case studies can provide not only completed cycles, but multiple completed cycles. This makes it easier to understand the dynamics of linked adaptive cycles and how they might change as systems organize. It also permits more in-depth monitoring of the slow-process, low- 
frequency events that appear essential to ultimate system resilience (Carpenter et al. 1999, Scheffer et al. 2001).

Second, the "deep time" perspective allows us to understand the ultimate, rather than the proximate, causes of the collapse of social and ecological systems. In particular, the long-term history of humanenvironment interactions contained in the archaeological record reveals that many human responses and strategies that apparently helped to increase resilience in the short term, or even over a few generations, nonetheless led to a serious erosion of resilience in the long term, resulting in the collapse of both environmental and social systems (McGovern et al. 1988, van Andel et al. 1990, Kirch et al. 1992, Kohler 1992, Rollefson and Köhler-Rollefson 1992, Redman 1999). It is only with the long-time perspective that we can identify which of many seemingly beneficial near-term actions truly contributed to long-term resilience, and the ways in which some outwardly rational choices led, in the end, to undesirable outcomes. The converse of this is that some social adaptations or cultural traditions may appear inefficient or "illogical" when viewed in the short term, but reduce risk and increase resilience in the long term (Butzer 1996). We return to this point below.

Third, an examination of human-environment interactions over sufficiently long time scales allows one to examine "true transformations" or truly novel situations (Brand 1999). These can be globally novel situations, such as the first-time emergences of agriculture, urban living, or industrial societies. In other cases, they may be only locally novel, i.e., not entirely new, but new to the people of a certain place and time. Examples of this include very different climatic conditions and rates of change, e.g., the end of the Pleistocene or the Little Ice Age; different available biota such as interactions with now-extinct species or communities; and changing sociopolitical organizations. It remains to be seen whether today's "Information Age" will represent a fourth revolution for modern humans following the first three of agriculture, urban living, and industrialization, resulting in fundamental transformations in the organization of human society and humanenvironment interactions. However, if it does, our understanding of the dynamics of past transformations and their implications for resilience may prove crucial in navigating the coming changes.
Fourth, the field of archaeology, when supplemented with the anthropological perspective, allows a rich understanding of the linked dynamics of human behavior and social and ecological systems across broad scales of organization ranging from individual households to hamlets, villages, cities, and civilizations. Few other social sciences encompass such a broad spectrum, preferring instead to concentrate more narrowly on "bottom up" (e.g., household, village) or "top down" (e.g., nation, state, levels of organization). If, as resilience proponents believe, the dynamics of a system are predicated on linked dynamics across scales, particularly the interaction of "fast" and "slow" variables, then examination of these linkages from both social and ecological perspectives will be crucial. Archaeological perspectives can provide critical bridges to fill some of the gaps left by present-day or near-historic studies focused on a narrower spectrum of human organizational scales.

Finally, the archaeological record allows us to identify those emergent features that appear to be inevitable, or at least highly probable, in societies as they become increasingly complex, including social stratification, compartmentalization of information, and, at certain scales, ecological simplification. The challenge before us will be to distinguish those features of social systems, and human interactions with the environment, that can be altered to achieve more desirable social and ecological outcomes, and those that are so much a product of history, human development, and biological, social, and cultural evolution that we must accept their constraints in fashioning our visions of the future. An archaeological perspective can contribute to meeting this challenge.

To appreciate the relevance of episodes from the past when dealing with problems of the present and future, two points must be understood. First, for at least the last 20,000-40,000 yr, people have been biologically and mentally indistinguishable from those of us alive today. Second, people in the past faced real environmental crises. There is little question that during the past $10,000 \mathrm{yr}$ we have modified, with increasing speed, our cultural trappings and social organizations, creating in the ensuing years environmental problems of increasing severity that are more global now than they were then. We must not, however, underestimate the impact that environmental crises had on people in antiquity (Butzer 1982, Crumley 1994, Redman 1999). Being forced by environmental degradation to abandon a homeland in 
which several generations of ancestors lived and died is a disaster that few of us face today. In terms of human decision making and the operation of socionatural ecosystems, the past has a great deal to tell us about how people confront threats to environmental sustainability.

\section{The paradoxes of resilience and adaptive capacity}

Much of the power of the panarchy approach is in its development of techniques to give meaning and context to common-sense notions of words like resilience, adaptive capacity, sustainability, collapse, and reorganization. At the core of this approach is the concept of "resilience," or the amount of change a system can withstand while retaining certain functions and/or structures (Rappaport 1968, Holling 1973, Levin 1999). Resilience is the ability of a system to remain functionally stable in the face of stress and to recover following a disturbance. Reducing this to a single word, it is the capacity to be flexible. One paradox of this concept is that a more resilient system implies more flexibility and hence less tight controls, but resilient systems are also defined as those able to maintain their controls and structure. An additional element of resilience theory is the recognition that systems and their contexts are continually changing, so resilience must also include a capacity for learning or restructuring new adaptations that often involve increased organizational complexity. This points to a second paradox, which is that resorting to increased social complexity to resolve problems seems to work in the short run while sometimes undermining the ability to solve them in the long term (Redman 1992, 1999:212, Tainter 2000:36).

These are but two of the apparent mismatches or paradoxes inherent in resilience theory. Cataloguing the features that contribute to resilience will reveal attributes that depend on the temporal, spatial, and organizational scales of interest, and on the phase of the adaptive cycle in which the focal system is situated. Attributes that confer resilience in the reorganization phase may erode it in the conservation phase, whereas attributes that confer resilience at the level of the state may erode it at the level of the household. The challenge for scholarship will lie in recognizing and elucidating these apparent mismatches and paradoxes, and the key to developing resilient strategies will lie in learning how to cultivate different social and ecological attributes at different times or at different levels.
Take, for instance, the case of social memory and system connectivity. Resilience theory recognizes these features as key adaptive elements that allow a system to retain its heterogeneity while remaining flexible enough to react to changing environmental and social contexts. This approach is similar to one advocated some time ago by anthropologists Marshall Sahlins and Elman Service (1960) when describing the "law of evolutionary potential." Adaptive capacity is enhanced by a rich social memory of alternative situations and responses, and by the accumulation of social capital in the form of the networks of trust, shared knowledge, and actual materials needed to facilitate those responses. At the same time, societies cannot always be buffeted by alternative responses; true resilience will lie in knowing when to change course and when to forge ahead. There is a cost to continually revisiting this question. Although system connectivity may be crucial in formulating a shared response in a timely fashion, too many connections may constrain response and lead to a "hypercoherent" situation in which excessive connections tend to make the system "brittle" or less resilient in the face of perturbations (Flannery 1972, Rappaport 1978). The key is in filtering information and fostering connectivity in times of stability, increasing exchange of information and fostering flexibility in times of change, and recognizing when a shift from one strategy to the other is necessary. Hence, we assert that there is no single optimal form of system connectivity or networking that will foster resilience, and that the most favorable level of connectivity will vary across the systems, and within a particular system across time.

A paradox, however, is that many human systems organize toward efficiency, which can reduce flexibility. What then happens to resilience? Efficient behaviors, such as specialization, reduction of redundancy, and streamlining of connectivity, allow a system to produce more at a lower cost of labor, materials, and energy and hence may bestow an advantage in a competitive context. Efficiency may allow a system to create and accumulate a surplus beyond its direct consumption needs and hence enable the concentration of power or the storage of capital. Stored capital may increase the resources available for adaptive behaviors, thus increasing adaptive capacity. It is this ability to accumulate a productive surplus that is a necessary, although not always sufficient, condition for the emergence of complex society. The growth of socially complex, hierarchical societies is a widespread, although not universal, process that has 
characterized much of human history. Individual cities, societies, and civilizations may have disappeared, but the longevity of the human experiment with efficiency, complexification, and stratification suggests that this is a strategy with significant staying power.

In contrast, these increasingly complex and apparently resilient societies of the past 10,000 yr emerged from the traditions of earlier human groups of huntergatherers and/or early agriculturalists who developed social networks and subsistence strategies that appeared, in the short term, to be inefficient. Nonetheless, societies that maintained seemingly inefficient strategies were often highly resilient, both at the level of the whole system (Netting 1993) and from the perspective of certain segments of society (cf. Adams 1978). The establishment of networks for the exchange of information, goods, and spouses, for instance, is a very ancient means of enhancing the resilience of otherwise vulnerable social groups. These networks are maintained through ceremonies, trade relations, political alliances, and other forms of reciprocity that exact a continuous cost in labor and materials (Rappaport 1968). The benefits, in contrast, may be experienced only infrequently, potentially skipping entire generations or accruing only to particular powerful segments of the current generation. Nonetheless, the introduction of apparent short-term inefficiencies to mediate risk in the long-term, either consciously or unconsciously, was a widespread practice. Although our culture retains some of these attributes of resilience today, our activities and alliances have shifted, and are more subject to the demands of immediate return on investment, and less subject to considerations of how costs today should be borne to mediate risks that may not appear for several generations.

This is, perhaps, a central conundrum of the human condition. There is an apparent cost to the system of self-organizing toward complexity (Tainter 2000). As systems become more complex, they usually channel as much productivity as possible to current operation, minimizing inefficiencies or redundancies in the process. This requires the system to maximize power (energy) output to support the emergent complex organization, but it does so by giving up significant adaptive capacity in other aspects of the system, such as those inherent in certain inefficient social and trade relationships. This raises a fundamental question: has the long-term, worldwide growth of complex society come at a significant cost to the overall resilience of society (Rappaport 1978)? Although theoretical considerations would answer that question in the affirmative, 10,000 yr of history say that increasing social and political complexity demonstrate the "success," or at least the popularity, of such a trajectory. Are our theoretical formulations incorrect? Can one substitute one reservoir of resilience (flexibility) for another (efficiency)? Or are we mistaking longevity for resilience?

\section{Contributions of resilience theory to archaeology}

The use of resilience theory is also expected to be of great benefit to archaeology as a discipline, because resilience theory bridges the gap between the theoretical and the practical. This might allow archaeologists to be more active participants in debates on contemporary issues (van der Leeuw and Redman 2002). Because of its new heuristic concepts and the broad comparative framework, resilience theory has the promise to create a new synthesis of components of archaeological analysis using new cross-disciplinary techniques and to foster an awareness of the relevance of newly defined categories of data.

The use of the figure-eight metaphor in Fig. 1 emphasizes the potentially cyclical nature of social and ecological systems and may lead one to equate this approach with the life-cycle metaphor of sequences of growth, senescence, death, and rebirth (e.g., Schumpeter 1987). Although at a very generalized level the life-cycle metaphor has value in conceptualizing cultural change, it has little explanatory value because it cannot account for the variability in forcing factors, scales of operation, and the actual diversity of trajectories of change. For the four reasons given above, the adaptive capacity metaphor provides a richer perspective on social and ecological changes and stability.

However, attempts by archaeologists to implement resilience theory in their own research might require further refinement of the model or further exchanges between archaeologists and other resilience scholars. The adaptive cycle and the notion that a system may pass through a series of phases with characteristic parameters, e.g., the axes and rates, provide an interpretive model that could unify disparate archaeological case studies, although at the same time this model is unsettling in that it suggests an underlying uniformity to cultural history. However, it may be even more difficult to obtain a clear 
understanding of what is intended by moving between "stability domains," i.e., knowing when a system "flips" to a new stability domain or undergoes "normal" change between phases within a single adaptive cycle. The question is whether small organizational adjustments are to be considered state flips or part of a normal phase trajectory. For example, revolt could occur if a small-scale entity, e.g., a family or cult, seized power, altering the attributes of higher levels of organization and giving rise to fundamentally new dynastic lines or political organizations that nonetheless retained many of the attributes of the eroded larger-level system.

We believe that one of the strengths of resilience theory is that the resilience of the system is usually investigated with reference to a particular set of properties. Continuity and change can be measured in terms of factors related to biology (e.g., are these the same people or their descendants?), social organization (e.g., does this form of government or community organization persist?), or life-style (e.g., is this the traditional way of doing things?). Some transformations may involve radical changes in all of these factors in concert, but we expect that many interesting state flips may involve factors from only one of these domains, while the others maintain continuity. In fact, from a forward-looking viewpoint, it might be important to contemplate which aspects of society or at what scales one is willing to let change occur as long as other attributes and scales of the society are preserved.

We also recognize that a phenomenon that is considered to be a phase trajectory at one scale of analysis may be considered a "state flip" at another. Distinguishing between the two could degenerate into an argument over semantics, and we believe that this determination can best be made on a case-by-case basis that takes into account the specifics of the definitions, scales, and objectives of the research. However, we also believe that archaeology could help enrich the approach to this question. Among the issues related to whether or not a system has flipped would be whether it has maintained the structures, controls, and members that are considered essential to its identity, and on what time scales a change in values can be considered to be a perturbation rather than a flip. In this way, the debate is no longer semantic, but focuses on discovering what the investigator considers to be the essential characteristics of a particular system. What remains the same when the system changes, how much of the system must change, and for how long must this change be maintained before the system's state is considered to have changed? This leads the researcher and the policy analyst to the logical questions about which aspects of a system we are willing to see changed, which aspects are important to maintain and toward what end, and whether system operations at a smaller scale or in another place should be sacrificed for the sustainability of the larger system or the local place (Folke et al. 2002:5-8).

We see in the archaeological and historical record many cases in which a society has undergone a minor adjustment or reorganization to maintain itself. One interpretation could be that each one of these adjustments represents an entire adaptive cycle; the other is that this is an expected part of the transition to the $\mathrm{K}$ conservation phase or of efforts to maintain the system within the $\mathrm{K}$ phase. In the example of ancient Mesopotamia we describe (see Case Study 1), the separate dynasties could be viewed as part of one long adaptive cycle, or every dynasty could be considered a different adaptive cycle in its own right, with each exhibiting reorganization, exploitation, conservation, and release. Again, it may be a simple matter of scale: if the resilience of individual dynasties is the main concern, then each one can be viewed as its own adaptive cycle. On the other hand, if the focus is on the resilience and evolution of a broader civilization, then it may be more appropriate to view these dynasties as phase changes within a single adaptive cycle or several cycles of the same basic kind. We believe that most historians would view this situation as multiple cycles, whereas resilience theory would be more inclined to regard it as representing the dynamics and patterns of the single overarching cycle. This has relevance to the present day as well: should the long cycle of sustained growth of population, economies, and technological capability in Western societies since the Renaissance be seen as a passage along a portion of a single adaptive cycle, or as multiple adaptive cycles? What are the implications for our understanding of resilience and the long-term integrity of our socioecological systems of using one lens or the other to view the system?

The positive results of a collaboration between archaeologists and resilience researchers will not flow in just one direction, but will be mutually beneficial. On a substantive level it will contribute to the ultimate objective of both groups, which is to reach a better understanding of the operation and future of human ecosystems. After all, our purpose is not to understand 
history per se, but to use history to formulate an understanding of problem solving that can clarify our situation today (Tainter 2000:4). On a collegial level, it provides the theoretical and practical basis for cooperation and sharing of ideas across traditional disciplinary divides. On a personal level, this collaboration will sensitize individual participants trained in different disciplines to the different perspectives they each hold, will help to clarify these differences, and will allow participants to seek ways to advance by embracing rather than avoiding those differences.

\section{RESILIENCE FROM THE PERSPECTIVES OF THE NATURAL AND SOCIAL SCIENCES}

Ecological systems have intrinsic temporal rhythms driven by factors such as generation time, age of reproduction, and disturbance frequencies. They also exhibit patterns on characteristic spatial scales driven by, e.g., dispersal distance, topography, and interaction lengths. However, these ecological systems also bear the signature of human institutions that act, either directly or indirectly, to alter the dominant spatial and temporal modes, e.g., suppressing fire frequencies or homogenizing landscapes, or to introduce new ones, such as 5-yr planning cycles or rectangular state boundaries (Pyne 1982, Carpenter and Gunderson 2001, Scheffer et al. 2001, Turner et al. 2002). At the same time, human institutions are shaped and influenced by the environmental rhythms and ecological arrangements of the biogeographic region in which they emerged (Cronon 1983, Diamond 1997, Dove and Kammen 1997, Ostrom 1990, Berkes and Folke 1998). This reciprocal "imprinting" of scales means that scientists and managers cannot effectively parse landscapes into "natural" and "human" components, but instead must study them as an integrated whole (National Research Council 1999, Kinzig et al. 2000, Michener et al. 2001, van der Leeuw and Aschan-Leygonie 2001).

Nonetheless, in seeking to understand integrated social and ecological systems, many of us still address the questions using the approaches, concepts, and paradigms of our home disciplines. We risk misinterpreting or misrepresenting the patterns and processes in the system if broad generalizations from one disciplinary framework do not fit nicely into another. This is another argument for promoting, whenever possible, collaboration between ecologists and archaeologists in particular, and natural and social scientists more generally.
In this final section, we select three key features of social and ecological systems that can appear to be very different when viewed from the perspectives of the natural vs. the social sciences. These are crossscale linkages and dynamics, information flow within the panarchy, and the four phases of the adaptive cycle.

\section{Characteristic scales and cross-scale interactions}

At the heart of resilience theory is the notion of linked dynamic cycles across spatial and temporal scales. We discuss here some features of these linked dynamic cycles from both the ecological and archaeological perspectives, the notion of "lumpiness," the relationship between "small-and-fast" and "large-andslow" cycles, and the "perception" and "selection pressures" of different levels in the panarchy.

Resilience theorists assert that the attributes of biological entities form clumped patterns that reflect panarchical organization, but, to date, providing simple rules for which scales emerge under specific conditions eludes them (Holling et al. 2002:405). For instance, if all the birds in a particular area are ranked according to body mass, a "lumpy" pattern emerges, with certain body masses preferred and others largely absent (Holling 1992). There is also evidence that those species exhibiting body masses on the edges of the preferred range are the most vulnerable to extinction, although it is also the edges that provide the greatest opportunities for colonization and invasion (Lambert and Holling 1998, Allen et al. 1999). Therefore, the edges represent both greater risk and greater opportunity.

The archaeological record complements this perspective. It seems clear from an examination of both ancient and modern human systems that they do not self-organize in a continuum of unit sizes, but distribute themselves in a series of favored sizes. These favored sizes are determined by social and organizational constraints, such as maximum group sizes that allow for an undifferentiated society or the minimum sizes required for a full range of subsistence activities under specialization. Indeed, the literature on central place theory (Berry 1967) and rank-size relationships (Johnson 1977) demonstrates the pervasiveness of discontinuous distributions of settlement size in early state societies and suggests some promising explanations for their existence. The human world is lumpy. It also appears that 
discontinuities such as transition zones between ecological systems or between discrete spheres of economic or social activity provide opportunities for entrepreneurial activities (Barth 1962, 1967) that are a major force in social and ecological change (Boone et al. 1990:631). Because these discontinuities provide opportunities, humans actively work to create discontinuities, e.g., territories, and reinforce the lumpy nature of human activities.

Resilience theorists also assert that there is a distinct space-time relationship in the distribution of these lumps. In particular, systems that operate at small scales are assumed to move quickly, whereas those at the top of the nested hierarchy of adaptive cycles are assumed to move slowly (Holling 2001, Gunderson and Holling 2002). It is the interaction between "small-and-fast" and "large-and-slow" that determines the resilience dynamics of the system. Large-and-slow adaptive cycles can provide the inertia and memory that permit small-and-fast adaptive cycles to pass through release and reorganization while maintaining similar functions, i.e., staying within the same basin of attraction. Conversely, if the nested adaptive cycles are "overconnected," release at the small-and-fast scale may, in cascading fashion, trigger release at the largeand-slow scale, precipitating potential shifts into new basins of attraction at large scales (see Fig. 2).

We frequently observe the same type of relationship in human systems: lower levels of social organization can change rapidly, whereas higher levels of social organization may appear to have more inertia. However, this relationship is far from universally true. Many small-scale entities, such as nuclear families of subsistence farmers, act conservatively, with strong traditions that are slow to change. At the top of the hierarchy, in contrast, there can be rapid change, as in the fall of a dynasty or the change of an administration. This dynamic may reverse the "revolt" and "remember" cycles as they have usually been portrayed in the resilience literature, where revolt occurs at the lower levels of organization and propagates to higher levels, while remember constraints are imposed in a top-down fashion. Numerous historic and prehistoric case studies lead us to expect that strong traditions at the lowest social level provide a repository of much information that might be key to a remember transition, whereas the vulnerability of the highest levels of a system to outside perturbations may make them the source of many revolt transitions.
This has implications not only for the adaptive cycles of human systems undergoing change, but for the dynamics of change in the ecological systems to which they are coupled. It is the interaction of adaptive cycles across these linked spatiotemporal scales, in particular the linkage between fast and slow cycles, that determines the dynamics and resilience of complex systems. In ecological systems, the links between fast and slow emerge as the result of selection pressure at the level of the individual or social group, shaped by the existing biotic and abiotic environments, including their characteristic spatiotemporal signatures and their changes over time. These links between fast and slow may differ among different ecological systems and will also change as systems evolve and develop, but the emergent links are the result of biogeophysical interactions, and can be expected to be similar for similar systems. In contrast, human behaviors and responses can often skew the links between fast and slow. Humans, for instance, seem to manage high-frequency events by attempting to shift them to occur at a lower frequency (e.g., management of floods, forest fires). At the same time, although the "memory" of very distant events contained in particular gene combinations is eventually lost in ecological systems as nearer-term selective pressures come to dominate the community structure, distant events encoded in tradition and culture can continue to shape human responses and potentially have the same force as near-term events in dictating trajectories. The ways in which these two forces, i.e., the shifting of high-frequency events and the memory of rare events, play out will vary from human group to human group, depending on culturally created perceptions of the proper role of human intervention in the environment and on the social memory of past experiences of environmental variability and extreme events. In other words, human systems are less predictable than ecological ones, and explanation or prediction requires more factors, including historical and cultural contingencies that can sometimes elude generalization or simplification.

\section{Information flow in ecological and human systems}

Information is clearly a key link among adaptive cycles within the panarchical system. We concentrate here on two aspects of information flow in ecological and human systems: the context in which information is being transmitted and responses made, and the ways in which different levels of the hierarchy shape information networks. 
The way in which signals are being sent within a system differs for the ecological and social components of the system, both in the rapidity with which signals for responding to change can be propagated and in the filtering that can occur. "Information" in ecological systems is largely encoded in gene combinations that allow adequate performance under particular environmental conditions. In ecological systems, new information can be created on evolutionary time scales as the result of mutation and/or natural selection and transmitted on ecological time scales as the result of invasions or other disturbances. Ecological systems can begin responding to a change immediately, because selection is driven by the "true" or extant context in which the ecological system finds itself. At the same time, that response can be slow, because it is constrained by the machinery of natural selection and genetic inheritance. This means that the "optimal" evolutionary outcomes always lag behind the environmental conditions under change. This slowed transmission of information in ecological systems can be considered a strength, because rapid adaptation to extant conditions might eliminate the genetic diversity that would be required to respond to future altered conditions.

Human societies, on the other hand, may not be responding to the "true" or extant environmental context, but rather to an earlier constructed and remembered context that is the product of tradition, which can have elements of denial, or misinformation intended for purposes of political manipulation. This type of response inertia is likely to be adaptive for ephemeral or high-frequency changes and potentially catastrophic for long-term and large-scale change. Transmission of information about society or its environment is an excellent medium for communicating an ideology or viewpoint about the phenomena in question that embodies both an "objective" reality and a reality "constructed" by the sender. Thus, there may be a significant lag between changing environmental conditions and human response. Human systems create and pass on culture, which, simply put, comprises symbols, meanings, and behaviors about traditional ways of doing things. The social forms we call societies are kept intact through the process of sharing this information by means of socialization, sanctions, and direct communications as well as via ceremonies, myths, and iconography. Thus, the ways in which a society filters and conveys knowledge at a variety of levels of organization is itself an essential element in the resilience of that society. The culture of a society creates structures that in a reciprocal manner facilitate or constrain the subsequent flow and content of information (see "bounded rationality" in Tainter 2000:5). This knowledge often encodes the perceived, remembered, and reconstructed historical experience of environmental variability and extreme events and the perceived, remembered, and reconstructed ways that societies of the past reacted to these challenges. Taken together with other categories of traditional knowledge, this forms the social memory of a society (Berkes 1999, McIntosh et al. 2000a).

However, once the response begins, it can be quite rapid, because it is not constrained by the need to achieve genetically based alterations in behaviors and strategies. Entirely new behaviors and strategies can appear within the space of a single generation, and human response, through anticipation and foresight, may even precede environmental or ecological change. The actual speed with which information travels between individuals or groups depends on the connectedness of these components of the system and whether they are able to successfully understand the message. This relies on the ability of a particular receiver to perceive the message and to give it meaning based on his or her experiential repertoire and on the socially agreed upon framework for how the world works (Gell-Mann 1994:17). These frameworks may be widely shared, but each society, or individual for that matter, will have its own social memory, which is a repository of experiential knowledge. Together these help guide the range of possible interpretations and responses to messages, which in effect puts contextually determined boundaries around our ability to perceive inputs and take action (Gladwin 1980). Some patterns may derive from very old experiences, such as the Egyptian concept of seven drought years being followed by ample river flow that is at least as ancient as the Old Testament, but continues today as a paradigm for monitoring the modern flow of the Nile (Hassan 2000).

Of special interest in the operation of the panarchy are the effects of information moving between systems that operate on different scales or levels of organization that frequently, but not always, correlate with spatial scales. "Top down" signals in human societies are delivered through laws, decrees, taxes, or other forms of coercion. Signals that travel "bottom up" may be less effectively delivered, because information generated at the lowest levels of society may be degraded or eliminated before it reaches the top. This means that "selection" can occur at the top 
administrative level, although it need not, in the form of devised strategies are intended to ensure the continuation or longevity of that level of organization. It may also mean that those institutions at that highest level of organization do not have the information they need from the lower levels. In ecological systems, on the other hand, selection occurs at the level of the gene, individual, kin group, or other social group to adapt those lowest levels of organization to changing conditions. There is no selection for improved or optimal functioning at the highest levels of organization, e.g., ecosystems, and no purposeful manipulation of information.

Because of the differing degrees of connectedness and inclusiveness of systems operating at differing levels of social organization, we expect that each level will have its own characteristic modes of information flow as well as sharing some cross-level mechanisms for communication. To be effective in motivating system responses, information on environmental or social phenomena received at a particular scale must be conveyed to the members of the system operating on the scale appropriate to that phenomenon, although the information may first have been received by members operating at smaller or larger scales within the system. The control of information flow is one of the essential tools used in creating and maintaining sociopolitical hierarchies. Interestingly, we hypothesize that the most effective information flows between two or more systems occur when information is exchanged at a similar level in the hierarchy, that is, horizontal exchange. This may occur because the sender and the recipient share more similar social positions, goals, and resources than when information travels up or down the hierarchy. Horizontal information exchange is a fundamental element of a historically important political formation, such as peer-polity interaction, that functions through a cycle of competitive emulation among neighboring rulers (see Case Study 2). In these circumstances, leaders of neighboring sociopolitical units of roughly the same scale attempt to outdo the neighboring polity, often leading to extraordinary displays, excessive consumption, and resulting increases in social hierarchy to support these activities that we may have seen among the Early Dynastic Mesopotamian city states as well as the platform mound communities of the Hohokam during the Classic period (Renfrew and Cherry 1986, van der Leeuw and McGlade 1997:341-343, Rice 1998).

Although information is essential to system operation and change, it must be noted that archaeology has both strengths and weaknesses in this domain. Although some information is encoded in material remains, including information about behavioral patterns, the content of much of the information held by the members of a society may not be visible to the archaeologist. This is especially true in the case of individuals, but it may also be true for the information held by groups or even by the society at large. Issues of misperception, lags in perception, or the scales at which perception is operating may not be easily accessible to the archaeologist, and we may have to rely on historical case studies for the time depth we desire. All is not lost, however, because if the act of perception leads to a response and associated action, then it is more likely to be detectable in the archaeological record. Hence, it may be useful to conceptualize the process as a series of steps: a signal is generated, it is perceived, a response may be made, and this action yields results. Each of these steps in the process operates on a specific spatial scale and each may have a characteristic lag from the step before. The resilience of a system will depend on how effectively the scales of perception and action are matched to those of the signal and the needed results, as well as whether the lags between steps are short enough to allow for a satisfactory response. It is probably most realistic for archaeologists, or virtually any social scientist, to focus on measuring the lag between the signal and the response or between the response and its result. Hence, the archaeological perspective would be better for measuring the results of perception rather than the particular characteristics of the perception itself.

When talking about perceptions of people in the past, it is also important to recognize the effects of our own patterns of perception on what we are studying. Just as we have characteristic ways of looking at humanenvironmental relationships today (e.g., that most human actions degrade the environment), people of the past had their own world view (that mobility is the "natural" solution to human-environmental stresses). Those viewpoints that seem inherent to the members of a society may be implicitly held as part of the culture itself, or they may be explicitly promulgated as in an ideology. Often the definition of what is appropriate is tightly tied to the context of the individual, group, or society. Although context has obvious environmental parameters, it also has social, economic, political, and ideational characteristics. It is sometimes very hard to understand the implications of the context you live in, because it is at the basis of your own understanding. "If fish were scientists, the 
last thing they'd discover would be water" (T. Allen, personal communication) is a warning to us all that we may be less aware of our own perspective and the context we live in than we imagine. There are two issues here: the first is the difficulty of knowing what things "mean" to the members of a particular society unless you are a member of that society and have been socialized to know those meanings. This would indicate that, to understand a society, you must examine it from the inside, something archaeologists cannot do very accurately. The second, and probably greater, issue is that it is very hard to be objective about yourself, your own society, or your perspectives. This is a major advantage we have when studying societies other than our own and societies from time periods other than the present. As outsiders we may lose some richness of understanding of the internal content of the system, but we gain a more objective perspective on the system's context.

\section{Elaborating the phases of the adaptive cycle}

A fundamental difference between the adaptive cycle model as it is applied to human systems and to nonhuman ecosystems is that humans are both participants in the process of change and sometimes attempt to manipulate both their position on the phase curve and the outcomes of state flips. There are those who, for whatever reason, may anticipate, correctly or incorrectly, imminent growth, collapse, or periods of reorganization and adjust their behaviors accordingly. It can be argued that societies often take deliberate action to ensure that they are in the $\mathrm{K}$ phase most of the time. The $\mathrm{K}$ phase is seen as a society that is approaching the potential carrying capacity of its environment and is attempting to "conserve" that position with its high production and high accumulation of capital or is even attempting to raise the carrying capacity through refinements in technologies or strategies. Sometimes, in an effort to maintain the larger system, decisions are made that sacrifice the productivity or even the well-being of smaller members of the system (Adams 1978). There are many situations in which energy per capita or, more importantly, energy per labor unit input may be declining, yet the energy production of the overall system is increasing (Boserup 1965, 1981). This need for the human component of a system to continue to increase its labor inputs to maintain resilience appears to be a repetitive pattern in human societies (Netting 1993). Contemplating these situations brings us to ask the Resilience Alliance and their archaeological collaborators for answers to several fundamental questions. What happens in human-sustained, intensive systems over very long periods of time? Do they always attempt to grow? Can stable plateaus be maintained? Is collapse inevitable?

Because the $\Omega$ and $\alpha$ phases of the adaptive cycle often receive inadequate attention in social and historical sciences, they tend to be poorly understood. This derives partly from the fact that many historical studies see the collapse of a civilization as the end of the discussion, because the period, dynasty, or even society appears to be at an end. Happily, resilience theory recognizes that collapse, release, and reorganization are just as integral as the exploitation/growth phase. Because the $\Omega$ to $\alpha$ phase can happen quickly, thrusting the top levels of government or society into disarray, record keeping during these periods is often poor, which can inhibit detailed reconstructions. Interestingly, it appears that the apparatus we call government seems to be replaced more often than the key elements of the society it ruled over. Sometimes the shell of the old system, e.g., the government or social organization, survives the collapse and is reused. At other times after a collapse, the system devolves to a lower level with potential subsequent reintegration. During periods of reorganization of human systems, the focus is usually on social, political, or economic organization rather than on ecological management, even if it was an ecological threat that toppled the previous system. For this reason, the need for detailed historical information when record keeping may be at a low point reinforces the potential contribution of archaeological studies.

\section{CONCLUSIONS}

All of these phenomena combined, including the "breaking" of the small-fast vs. large-slow linkages in human systems relative to ecological ones, the different selective contexts, the rapidity of the response, and the way in which the information in these systems is filtered, will have implications for how social and ecological systems are coupled, and for the critical scales at which the strongest "mismatch" between environmental change and appropriate human response might occur to precipitate crises. The challenge for management is to develop institutional structures that match the ecological and social processes that operate at different spatial and temporal scales and that address the links between those scales (Folke et al. 2002:21). Our understanding of the mechanisms leading to resilience in ecological systems, or in ecological systems coupled with 
traditional societies embedded in a modern age, may be insufficient for understanding the emergent properties of the coupled human-ecological systems, with their potentially very different characteristic spatial and temporal scales and modes of propagation. Again, the archaeological record can be of assistance in extending the number and types of coupled systems examined, and thus help to distinguish robust generalizations from more idiosyncratic responses.

The study of resilience and state flips in ecological, human, or coupled human-ecological systems can be viewed as a purely intellectual activity intended to cast light on the intricacies of nonlinear dynamics, crossscale interactions, and complex adaptive systems. On a practical level, however, those engaged in elucidating system resilience hope that their work can be applied to improving the sustainability, adaptive capacity, and functioning of prevailing social and ecological systems. In one variant of this approach, the goal is adaptive comanagement in which a long-term management structure permits stakeholders to share management responsibility within a specific system of natural resources and to learn from their actions (Ruitenbeek and Cartier 2001). Moreover, the authors argue that this type of management is an emergent property of a complex bio-economic system. We do agree that adaptive management seems often to have prevailed in prehistory and history, but that there are at least as many situations where it either did not emerge or what did emerge was not sufficient to maintain the individuality of the system. We cannot assume that human systems left to their own will save themselves.

One aspect of improving our ability to flexibly manage and respond for resilience lies in understanding the "early warning" indicators of undesirable state change. Perceptions of and responses to such indicators must occur prior to the point at which intervention would be ineffective or useless. Cross-scale interactions in coupled systems may play out in complex ways, and, given our inability to monitor and analyze all possible scales for signals simultaneously because of resource and time constraints, it is crucial to identify the "critical scales" at which early-warning indicators both emerge and can be perceived while we still have time to respond to them. These critical scales may themselves change as systems develop. Even if we are able to identify these critical scales, it still leaves open the more complex question of which among the many environmental signals humans choose to respond to and what determines the repertoire of alternative responses (Gladwin 1980, McIntosh et al. 2000b).
Evaluating the resilience of a specific system requires a special sensitivity to lags and scale mismatches. What lags in perception, decision, and response can be tolerated? What mismatches in monitoring scale and response scale can be tolerated? What are the effects of mismatches? As humans identify important environmental signals, they tend to build institutions to help contextualize and deal with them. This may be as simple as a single set of instructions for coping with the signal or may grow to be a formal organization with a bureaucracy, regulations, and agencies for implementation. How the institutions that mediate human-environmental interactions emerge, what influences their character, and how effective their operation is are questions that underlie any ultimate understanding of system resilience (Ostrom 1990, 1999b, Ascher 2001).

The archaeological record may provide valuable information about the emergence of these critical scales, how their emergence is affected by intrinsic and different characteristics of human and ecological systems, and how they change over time or through organizational development. It will also provide multiple case studies of human response to changing environmental conditions, making it possible to assess the subset of environmental signals that key human perception and response. Our challenge is to learn these lessons of history well enough to repeat those worth repeating, and avoid those best left unduplicated.

\section{CASE STUDY 1: Adaptive Cycles of Centralization and Fragmentation in Ancient Mesopotamia}

It is widely believed that Mesopotamia was home to the earliest urban and state societies as well as the site of many other key innovations, such as writing, the wheel, the plow, and metallurgy. Debates about whether these seminal events occurred there first does not diminish the fundamental role that the early civilizations of Mesopotamia played in establishing a social organization, a political apparatus, and human attitudes toward the environment that have profoundly affected subsequent Western culture and history. Mesopotamian society emerged in the closely interacting nexus of a large arid alluvial basin, irrigation agriculture, intensified production of goods, trade, warfare, and increasingly hierarchical political organization; all of these contexts remain important today. 
By adopting the conceptual framework of societies moving through adaptive cycles in response to crossscale interactions, it may be possible to shed new light on a particularly pivotal period of world history, roughly 3500 to $2000 \mathrm{BC}$. This period is often divided into five episodes: the first three are archaeologically defined proto-historic phases, and the final two are historically recorded dynasties. Each of these episodes involved the establishment and abandonment of cities with their attendant rise and fall of rulers (Yoffee 1988) and hence could be conceptualized as individual adaptive cycles. However, in Fig. 3 we take a broader perspective and order these into a single 1500-yr adaptive cycle.

We start the cycle with Uruk Period settlements, many of which reached urban proportions, located all across greater Mesopotamia. Although various similarities in their material culture indicate that these widely dispersed communities shared a common cultural tradition or may have been in trade contact, there is little evidence to support any type of pan-regional administration (Algaze 1989). We would interpret this interval as part of the release phase of the adaptive cycle, in which great energy was made available by new forms of settlement in hitherto underoccupied regions. The following Jemdat Nasr period is hard to separate archaeologically, but it spanned a period of time when organizational structures were becoming more elaborate and writing and other arts were rapidly advancing. We would identify this as the beginning of the reorganization phase. By the end of this period, a relatively well-known trajectory of development that we portray in Fig. 3 was taking off in southern Mesopotamia (Redman 1978, Pollock 1999). Recent field research is unveiling equally impressive developments in northern Mesopotamia (Weiss et al. 1993, Wattenmaker 1998). The organizational developments of this and subsequent phases of Fig. 3 cannot have emerged by being "remembered," because they did not previously exist in the world. Hence they resulted purely from human experimentation and innovation.

The Early Dynastic Period began with a series of experiments in organizing cities and their hinterlands, as manifested in temple ovals, palaces, and royal burials, and culminated in an attempt at regionwide political alliances, i.e., the league of 50 city-states under Lugalzagesi (see Ezard 1967a). We view these developments as the formation of Sumerian civilization, which reflects the growth in social capital and connectedness of the $r$ to $K$ transition. In a very subjective assessment, many scholars consider this to be among the most creative and exciting periods of all human history. The remaining political autonomy of the Sumerian city-states disappeared when they were conquered by Sargon of Akkad, who established an ethnically distinct dynasty with the first Semitic rulers and what many consider to be the first nation-state (Redman 1978, Nissen 1988). Sargon is credited not only with the political unification of the region, but also with the establishment of a large administrative apparatus to manage its affairs. In ancient texts Sargon claims that a bureaucracy of 5400 worked at his palace in Akkad (Bottéro 1967). We view the creation of the Akkadian State as the culmination of the $\mathrm{r}$ to $\mathrm{K}$ phase, and its maintenance under Sargon's descendents as having the characteristics of the $\mathrm{K}$ phase.

Fig. 3. Proposed adaptive cycle for ancient Mesopotamian societies (3500-2000 BC). Note that historical periods overlap, but do not completely correlate, with the phases of the adaptive cycle.

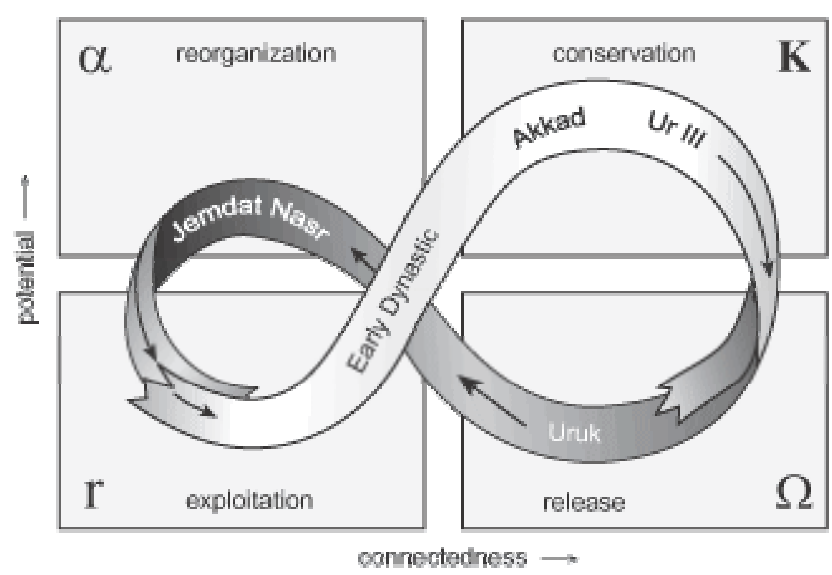

Following a short period during which rival city-states competed for suzerainty, a new regionwide state emerged: the Third Dynasty of Ur or Ur III (Ezard $1967 b$, Nissen 1988). A variety of organizational innovations such as a written code of law and more effective colonial administration allowed the rulers of this dynasty to extend their control over all of Mesopotamia. We view the beginning of this period as a continuation of the $\mathrm{K}$ phase featuring increased efforts by the controlling elite at the elaboration of administrative control (connectedness) and an expansion of the irrigation regime (intensification in the face of shortfalls). This led subsequently to an 
undermining of the long-term viability of the dynasty (Adams 1978, Redman 1999) and the "release and revolt" phase of the adaptive cycle. The decisions made by those at the top of the political hierarchy may have been seen by them as the logical alternative necessary to maintain their organization and lifestyle, yet different decisions probably would have been made by those at lower levels of the hierarchy who had different goals and more information on agrarian viability. Nevertheless, the short-term maximizing strategies of the rulers led to the salinization of large tracts of formerly productive farmland, resulting in the breakdown of the central political authority and the demise of not just this dynasty, but of Sumer as a dominant political force in Mesopotamia.

This period was followed by a short interlude in which political control was once again fragmented into local city-states and then reamalgamated into a regional nation-state. This type of oscillation continued for the next $1500 \mathrm{yr}$ as the focus of political authority continued to move to the north and to the uplands. This pattern stemmed from bad long-term management strategies that prevented the south from continuing to accumulate sufficient capital resources, despite its extraordinary agricultural potential.

Fig. 4. Proposed adaptive cycles related to a state flip in Hohokam society occurring during the pre-Classic to Classic Period transition. Although more complex in some ways, Classic Period Hohokam settlements extended over a smaller geographic range and the highest organizational level appeared to be more fragmented and competitive than their Pre-Classic predecessors.

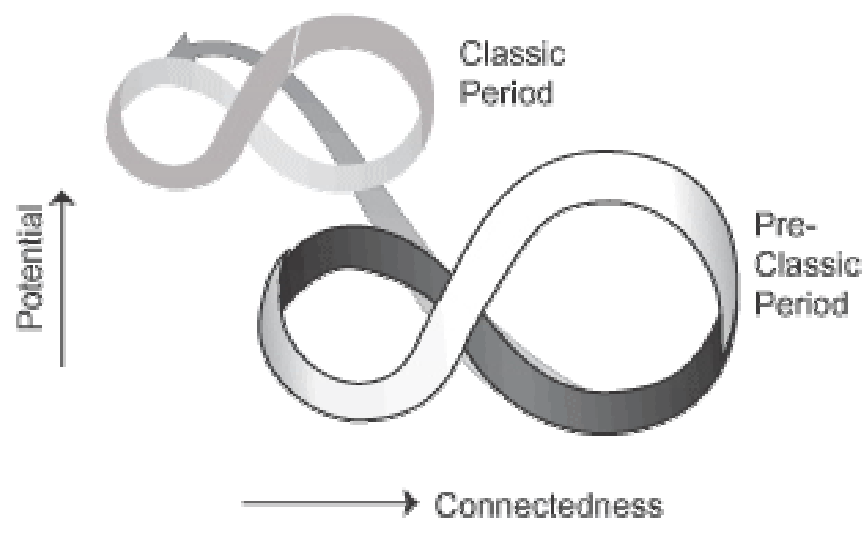

CASE STUDY 2: Irrigation and Society in the Desert Southwest

The Hohokam represent one of the great prehistoric cultural traditions of North America. Their settlements are found along the lowland river valleys in the desert region of central and southern Arizona. Some Hohokam settlements were occupied for only a few generations, but in selected locations, such as the basin occupied by the modern city of Phoenix, Hohokam communities existed for a millennium, up until about AD 1400. Although the population density of the Phoenix Basin ebbed and flowed, the persistence of these desert dwellers in that location is truly impressive. The centerpiece of their success was their irrigation system, which was built around the two rivers, the Salt and the Gila, that traversed the broad Phoenix lowland basin. These rivers ran year round, but their volume varied dramatically in response to runoff from rainfall and snowmelt in the upland catchments during the spring. The Hohokam took advantage of this resource by building hundreds of kilometers of canals, with some main trunk lines as long as $30 \mathrm{~km}$, to bring water and sediments to increasingly distant fields (Crown and Judge 1991, Howard and Huckleberry 1991, Abbot 2000, Doyel et. al. 2000, Bayman 2001). The Hohokam developed important social institutions to help organize themselves to overcome the difficulties in their environment. This resulted in large central communities with public architecture, such as ball courts and/or platform mounds that would be the focus of ceremonial and civic activities. Community organization provided the framework for allocating water from canals and mobilizing labor for constructing and maintaining the canal system.

We believe that the major forces driving Hohokam society through the adaptive cycle derived from the interaction of short- and long-term climate variability, available irrigation strategies, and social responses at varying spatial scales. In particular, a long period of relatively stable annual stream flow volumes allowed for the construction and subsequent expansion of irrigation systems on the Salt and Gila Rivers that were essential to the growth in population and social complexity that characterized the Pre-Classic Period Hohokam adaptive cycle that occurred during approximately AD 700-1150 (Fig. 4). A long period of increasing variability of water flows and possible deepening of the riverbed stressed the irrigation system to the point where Hohokam society experienced a serious transformation resulting in what 
archaeologists characterize as the Classic Period of AD 1150-1400 (Nials et. al. 1989, Rice 1998). We hypothesize that this represents a "release and revolt" reorganization of the system that projected it through a new adaptive cycle in which its geographic boundaries contracted and the upper level of its social organization fragmented. However, at the same time, it became more socially and politically complex, as demonstrated by the construction of platform mounds and "great" houses. Although this reorganization stabilized the society at a new level, it was not sufficiently resilient to maintain Hohokam society beyond AD 1400.

There has been an enormous amount of archaeological research in the Hohokam region during the past $20 \mathrm{yr}$, and this is supplemented by excellent paleoclimatic records derived from several sources. The initial impression derived from the record is that short-term political stability and economic maximization were achieved only by weakening the capacity of the productive system to react to internal and external challenges, which undermined the long-term survival of the Hohokam (Redman 1992, 1999). A working group of about 20 Southwestern archaeologists, paleoclimatologists, and modelers has begun to meet to examine these historical processes within a resilience theory framework.

Responses to this article can be read online at: http://www.consecol.org/vol7/iss1/art14/responses/index.html

\section{Acknowledgments:}

We thank the attendees of two workshops held in Tempe, Arizona, in the spring of 2000 for the stimulating discussions that launched this paper. They include Dave Abbott, Jean-Francois Berger, Keith Clarke, Jeffrey Dean, Peter Dunham, Paul Fish, Suzanne Fish, Anabel Ford, Michelle Hegmon, Marco Janssen, Keith Kintigh, Timothy Kohler, Owen Lindauer, Paul Minnis, Ben Nelson, Margaret Nelson, John Ravesloot, Glen Rice, Brenda Shears, Joseph Tainter, Phil Taylor, Sander van der Leeuw, Carla Van West, and Henry T. Wright. We thank Joseph Tainter, Sander van der Leeuw, Brian Walker, and Darrel Jenerette for their thoughtful comments on an earlier version of this manuscript, and Garry Peterson for his help with figures. This work has been supported by grants from the McDonnell Foundation and the Resilience Alliance.

\section{LITERATURE CITED}

Abbott, D. R. 2000. Ceramics and community organization among the Hohokam. University of Arizona Press, Tucson, Arizona, USA.

Adams, R. M. 1978. Strategies of maximization, stability, and resilience in Mesopotamian society, settlement, and agriculture. Proceedings of the American Philosophical Society 122:329-335.

Algaze, G. 1989. The Uruk expansion: cross-cultural exchange in early Mesopotamian civilization. Current Anthropology 30(5):571-608.

Allen, C. R., E. A. Forys, and C. S. Holling. 1999. Body mass patterns predict invasions and extinctions in transforming landscapes. Ecosystems 2(2):114-121.

Ascher, W. 2001. Coping with complexity and organizational interests in natural resource management. Ecosystems 4(8):742-757.

Barth, F. 1962. The role of the entrepreneur in social change in northern Norway. Universitietsforlaget, Bergen, Norway.

Barth, F. 1967. Economic spheres in Darfur. Pages 149-174 in R. Firth, editor. Themes in economic anthropology. Tavistock, London, UK.

Bayman, J. M. 2001. The Hohokam of southwest North America. Journal of World Prehistory 13(3):257-311.

Berkes, F. 1999. Sacred ecology: traditional ecological knowledge and resource management. Taylor and Francis, Philadelphia, Pennsylvania, USA.

Berkes, F., and C. Folke, editors. 1998. Linking social and ecological systems: management practices and social mechanism for building resilience. Cambridge University Press, Cambridge, UK.

Berkes, F., and C. Folke. 2002. Back to the future: ecosystem dynamics and local knowledge. Pages 121-146 in L. H. Gunderson and C. S. Holling, editors. Panarchy: understanding transformations in human and natural systems. Island Press, Washington, D.C., USA.

Berry, B. J. L. 1967. Geography of market centers and retail distribution. Foundations of Economic Geography Series. Prentice-Hall, Engelwood Cliffs, New Jersey, USA.

Boone, J. L., J. E. Myers, and C. L. Redman. 1990. Archeological and historical approaches to complex societies: the Islamic states of medieval Morocco. American Anthropologist 92(3):630-646.

Boserup, E. 1965. The conditions of agricultural growth. 
Aldine, Chicago, Illinois, USA.

Boserup, E. 1981. Population and technological change: a study of long-term trends. University of Chicago Press, Chicago, Illinois, USA.

Bottéro, J. 1967. The first Semitic empire. Pages 91-132 in J. Bottéro, E. Cassin, and J. Vercoutter, editors. The Near East: the early civilizations. Translated by. R. F. Tannenbaum. Delacorte Press, New York, New York, USA.

Brand, S. 1999. The clock of the long now: time and responsibility. Basic Books, New York, New York, USA.

Butzer, K. 1982. Archaeology as human ecology: method and theory for a contextual approach. Cambridge University Press, New York, New York, USA.

Butzer, K. 1996. Ecology in the long view: settlement, agrosystem strategies, and ecological performance. Journal of Field Archaeology 23(2):141-150.

Carpenter, S., W. Brock, and P. Hanson. 1999. Ecological and social dynamics in simple models of ecosystem management. Conservation Ecology 3(2):4. [online] URL: http://www.consecol.org/vol3/iss2/art4.

Carpenter, S. R., and L. H. Gunderson. 2001. Coping with collapse: ecological and social dynamics in ecosystem management. BioScience 51(6):451-457.

Cronon, W. 1983. Changes in the land: Indians, colonists, and the ecology of New England. Hill and Wang, New York, New York, USA.

Crown, P. L., and J. J. Judge, editors. 1991. Chaco and Hohokam: prehistoric regional systems in the American Southwest. School of American Research Press, Santa Fe, New Mexico, USA.

Crumley, C. L., editor. 1994. Historical ecology: cultural knowledge and changing landscapes. School of American Research Press, Santa Fe, New Mexico, USA.

Diamond, J. 1997. Guns, germs, and steel: the fate of human societies. Norton, New York, New York, USA.

Dove, M., and D. Kamman. 1997. The epistemology of sustainable resource use: managing forest products, swidden, and high-yielding variety crops. Human Organization 56(1) 91-101.

Doyel, D. E., S. K. Fish, and P. R. Fish, editors. 2000. The Hohokam village revisited. Southwestern and Rocky Mountain Division, American Association for the Advancement of Science, Glenwood Springs, Colorado, USA.

Ezard, D. O. 1967a. The early Dynastic Period. Pages 5290 in J. Bottéro, E. Cassin, and J. Vercoutter, editors. The Near East: the early civilizations. Translated by. R. F. Tannenbaum. Delacorte, New York, New York, USA.
Ezard, D. O. 1967b. The Third Dynasty of Ur-its empire and its successor states. Pages 133-176 in J. Bottéro, E. Cassin, and J. Vercoutter, editors. The Near East: the early civilizations. Translated by. R. F. Tannenbaum. Delacorte, New York, New York, USA.

Flannery, K. V. 1972. The cultural evolution of civilizations. Annual Review of Ecology and Systematics 3:339-426.

Folke, C., S. Carpenter, T. Elmqvist, L. Gunderson. C. S. Holling, B. Walker, J. Bengtsson, F. Berkes, J. Colding, K. Danell, M. Falkenmark, L. Gordon, R. Kasperson, N. Kautsky, A. Kinzig, S. Levin, L-G. Mälder, F. Moberg, L. Ohlsson, P. Olsson, E. Ostrom, W. Reid, J. Rockström, H. Savenije, and U. Svedin. 2002. Resilience and sustainable development: building adaptive capacity in a world of transformations. Environmental Advisory Council to the Swedish Government, Stockholm, Sweden.

Gell-Mann, M. 1994. The quark and the jaguar. Freeman, New York, New York, USA.

Gladwin, C. H. 1980. A theory of real-life choice: applications to agricultural decisions. Pages 45-85 in P. F. Barlett, editor. Agricultural decision making: anthropological contributions to rural development. Academic Press, New York, New York, USA.

Gunderson, L. H., and C. S. Holling, editors. 2002. Panarchy: understanding transformations in human and natural systems. Island Press, Washington, D.C., USA.

Gunderson, L. H., C. S. Holling, and S. S. Light, editors. 1995. Barriers and bridges to the renewal of ecosystems and institutions. Columbia University Press, New York, New York, USA.

Hassan, F. 2000. Environmental perception and human responses in history and prehistory. Pages 121-140 in R. J. McIntosh, J. A. Tainter, and S. K. McIntosh, editors. The way the wind blows. Historical Ecology Series. Columbia University Press, New York, New York, USA.

Holling, C. S. 1973. Resilience and stability of ecological systems. Annual Review of Ecology and Systematics 4:1-23.

Holling, C. S. 1992. Cross-scale morphology, geometry, and dynamics of ecosystems. Ecological Monographs 62(4):447-502.

Holling, C. S. 2001. Understanding the complexity of economic, ecological, and social systems. Ecosystems 4(5):390-405.

Holling, C. S., and L. H. Gunderson. 2002. Resilience and adaptive cycles. Pages 25-62 in L. H. Gunderson and C. S. Holling, editors. Panarchy: understanding transformations in human and natural systems. Island Press, Washington, D.C., USA. 
Holling, C. S., L. H. Gunderson, and D. Ludwig. 2002. In quest of a theory of adaptive change. Pages 3-24 in L. H. Gunderson and C. S. Holling, editors. Panarchy: understanding transformations in human and natural systems. Island Press, Washington, D.C., USA.

Howard, J. B., and G. Huckleberry. 1991. The operation and evolution of an irrigation system: the East Papago Canal study. Soil Systems Publication in Archaeology Number 18. Arizona Department of Transportation, Environmental Planning Services, Phoenix, Arizona, USA.

Johnson, G. A. 1977. Aspects of regional analysis in archaeology. Annual Review of Anthropology 6:479-508.

Kinzig, A. P., J. Antle, W. Ascher, W. Brock, S. Carpenter, F. S. Chapin III, R. Costanza, K. L. Cottingham, M. Dove, H. Dowlatabadi, E. Elliot, K. Ewel, A. Fisher, P. Gober, N. Grimm, T. Groves, S. Hanna, G. Heal, K. Lee, S. Levin, J. Lubchenco, D. Ludwig, J. Martinez-Alier, W. Murdoch, R. Naylor, R. Norgaard, M. Oppenheimer, A. Pfaff, S. Pickett, S. Polasky, H. R. Pulliam, C. Redman, J. P. Rodriguez, T. Root, S. Schneider, R. Schuler, T. Scudder, K. Segersen, M. R. Shaw, D. Simpson, A. A. Small, D. Starrett, P. Taylor, S. van der Leeuw, D. H. Wall, and M. Wilson. 2000. Nature and society: an imperative for integrated environmental research. Available online at http://lsweb.la.asu.edu/akinzig/report.htm.

Kirch, P. V., J. R. Flenley, D. Steadman, F. Lamont, and S. Dawson. 1992. Ancient environmental degradation. National Geographic Research and Exploration 8(2):166179.

Kohler, T. 1992. Prehistoric human impact on the environment in upland North American Southwest. Population and Environment: A Journal of Interdisciplinary Studies 13(4):255-268.

Lambert, W. D., and C. S. Holling. 1998. Causes of ecosystem transformation at the end of the Pleistocene: evidence from mammal body-mass distributions. Ecosystems 1(2):157-175.

Levin, S. A. 1999. Fragile dominion: complexity and the commons. Perseus Books, Reading, Massachusetts, USA.

McGovern, T. H., G. Bigelow, T. Amorosi, and D. Russell. 1988. Northern islands, human error, and environmental degradation: a view of social and ecological change in the medieval North Atlantic. Human Ecology 16(3):225-269.

McIntosh, R. J., J. A. Tainter, and S. K. McIntosh, editors. 2000a. The way the wind blows. Historical Ecology Series. Columbia University Press, New York, New York, USA.

McIntosh, R. J., J. A. Tainter, and S. K. McIntosh. 2000b. Climate, history, and human action. Pages 1-44 in R.
J. McIntosh, J. A. Tainter, and S. K. McIntosh, editors. The way the wind blows. Historical Ecology Series. Columbia University Press, New York, New York, USA.

Michener, W. K., T. J. Baerwald, P. Firth, M. A. Palmer, J. L. Rosenberger, E. A. Sandlin, and H. Zimmerman. 2001. Defining and unraveling biocomplexity. BioScience 51(12):1018-1023.

National Research Council. 1999. Our common journey. Board on Sustainable Development, National Academy Press, Washington, D.C., USA.

Netting, R. M. 1993. Smallholders, householders: farm families and the ecology of intensive, sustainable agriculture. Stanford University Press, Stanford, California, USA.

Nials, F. L., D. A. Gregory, and D. A. Graybill. 1989. Salt River stream flow and Hohokam irrigation systems. Pages 59-78 in D. A. Graybill, D. A. Gregory, F. L. Nials, S. Fish, R. Gasser, C. Miksicek, and C. Szuter, editors. The 19821998 excavations at Las Colinas: environment and subsistence. Arizona State Museum Archaeological Series, Number 162. Arizona State Museum, Tucson, Arizona, USA.

Nissen, J. H. 1988. The early history of the Near East 9000-2000 B.C. Translated by E. Lutzeier. University of Chicago Press, Chicago, Illinois, USA.

Ostrum, E. 1990. Governing the commons: the evolution of institutions for collective action. Cambridge University Press, Cambridge, UK.

Ostrom, E. 1999a. Coping with tragedies of the commons. Annual Reviews of Political Science 2:493-535.

Ostrom, E. 1999b. Linking social and ecological systems: management practices and social mechanisms for building resilience. Ecological Economics 28(1):151-153.

Pollock, S. 1999. Ancient Mesopotamia: the Eden that never was. Cambridge University Press, Cambridge, UK.

Pyne, S. J. 1982. Fire in America: a cultural history of wildland and rural fire. Princeton University Press, Princeton, New Jersey, USA.

Rappaport, R. A. 1968. Pigs for the ancestors: ritual in the ecology of a New Guinea people. Yale University Press, New Haven, Connecticut, USA.

Rappaport, R. A. 1978. Maladaptations in social systems. Pages 49-87 in J. Freidman and M. J. Rowlands, editors. The evolution of social systems. University of Pittsburgh Press, Pittsburgh, Pennsylvania, USA.

Redman, C. L. 1978. The rise of civilization: from early farmers to urban society in the ancient Near East. W. H. Freeman, San Francisco, California, USA. 
Redman, C. L. 1992. The impact of food production: shortterm strategies and long-term consequences. Pages 35-49 in J. E. Jacobsen and J. Firor, editors. Human impact on the environment: ancient roots, current challenges. Westview Press, Boulder, Colorado, USA.

Redman, C. L. 1999. Human impact on ancient environments. University of Arizona Press, Tucson, Arizona, USA.

Renfrew, A. C., and J. F. Cherry, editors. 1986. Peer policy interaction and socio-political change. Cambridge University Press, Cambridge, UK.

Rice, G. 1998. War and water: an ecological perspective on Hohokam irrigation. Kiva 63(3):263-301.

Rollefson, G. O., and I. Köhler-Rollefson. 1992. Early Neolithic exploitation patterns in the Levant: cultural impact on the environment. Population and Environment: A Journal of Interdisciplinary Studies 13(4):243-254.

Ruitenbeek, J., and C. Cartier. 2001. The invisible wand: adaptive co-management as an emergent strategy in complex bio-economic systems. Occasional Paper Number 34. Center for International Forestry Research, Jakarta, Indonesia.

Sahlins, M. D., and E. R. Service, editors. 1960. Evolution and culture. University of Michigan Press, Ann Arbor, Michigan, USA.

Scheffer, M., S. Carpenter, J. A. Foley, C. Folke, and B. Walker. 2001. Catastrophic shifts in ecosystems. Nature 413(6856):591-596.

Schumpeter, J. A. 1987. Capitalism, socialism and democracy. Sixth edition. Unwin, London, UK.

Tainter, J. A. 1988. The collapse of complex societies. New Studies in Anthropology. Cambridge University Press, Cambridge, UK.

Tainter, J. A. 2000. Problem solving: complexity, history, sustainability. Population and Environment 22(1):3-41.

Turner, B. L., D. R. Foster, and J. Geoghegan. 2002. Land change, science and tropical deforestation: the final frontier in southern Yucatan. Oxford University Press, New York, New York, USA.

van Andel, T. H., E. Zangger, and A. Demitrack. 1990. Land use and soil erosion in prehistoric and historical Greece. Journal of Field Archaeology 17:379-396.

van der Leeuw, S., and C. Aschan-Leygonie. 2001. A long-term perspective on resilience in socio-natural systems. Working Papers of the Santa Fe Institute, Number 01-08-042. Sante Fe Institute, Santa Fe, New Mexico, USA. Available online at http://www.santafe.edu/sfi/publications/01wplist.html. van der Leeuw, S., and J. McGlade. 1997. Structure change and bifurcation in urban evolution: a non-linear dynamical perspective. Pages 331-332 in S. E. van der Leeuw and J. McGlade, editors. Time, process and structural transformation in archaeology. Routledge, London, UK.

van der Leeuw, S., and C. L. Redman. 2002. Placing archaeology at the center of socio-natural studies. American Antiquity 67(4):597-605.

Wattenmaker, P. 1998. Household and state in upper Mesopotamia. Smithsonian Institution, Washington, D.C., USA.

Weiss, H., M.-A. Courty, W. Wetterstrom, F. Guichard, L. Senior, R. Meadow, and A. Curnow. 1993. The genesis and collapse of third millenium north Mesopotamian civilization. Science 261:995-1003.

Westley, F. 1995. Governing design: the management of social systems and ecosystems management. Pages 391-427 in L. H. Gunderson, C. S. Holling, and S. S. Light, editors. Barriers and bridges to the renewal of ecosystems and institutions. Columbia University Press, New York, New York, USA.

Yoffee, N. 1988. The collapse of ancient Mesopotamian states and civilization. Pages 44-68 in N. Yoffee and G. L. Cowgill, editors. The collapse of ancient states and civilizations. University of Arizona Press, Tucson, Arizona, USA. 